\title{
Prevalence of Benign Breast Disease and Risk of Malignancy in Benign Breast Diseases
}

\author{
Dr. Vijayalakshmi $\mathrm{M}^{1}$, Dr. J Yadigiri Rao ${ }^{2}$, Dr. T.Y. Shekar ${ }^{3}$ \\ Dr. Shobha Balakrishnan ${ }^{4}$, Dr. Divya $\mathrm{M}^{5}$, Dr. Sameera $\mathrm{K}-\mathrm{Jr}^{6}$, \\ Dr. Alekya $\mathrm{N}-\mathrm{Jr}^{7}$, Dr. Aravind JVNK - $\mathrm{Jr}^{8}$. \\ Department of General Surgery. Mediciti Institute of Medical Sciences, Ghanpur, \\ Medchal, RR District - TS India.
}

\begin{abstract}
Introduction: Woman breast is a dynamic structure undergoes proliferative changes during reproductive period and changes of involution occur in perimenopausal period. Benign breast disease is most common problem in woman. Majority of them require treatment in their life time. Benign breast disease constitutes a heterogeneous group of lesions; include developmental abnormalities, inflammatory lesions and neoplasms. Benign lesions are likely to turn malignant, it is a major concerned to patient as well as clinician, aim of a clinician is to rule out breast cancer since, most benign lesions occur in cancer age group and some of them mimic as carcinoma.

Material and methods: Present study is a retrospective/prospective study, carried out in the department of MediCiti Institute of Medical Sciences. We had come a crossed 100 benign breast neoplasms out of 145 breast cases admitted during the said period. Out of which 70 cases were fibro adenomas, followed by 20 fibrocystic diseases and 8 phyllodes tumour and one adenomyoepithelioma and one plasma cell mastitis. Fibro adenoma was most common benign tumour in our study followed by fibrocystic disease and phyllodes tumour of the breast. Out of 20 cases of fibrocystic disease, one was reported as carcinoma and out of 8 phyllodes tumour 2 were reported as malignant. Among variants of fibro adenomas, two giant fibro adenomas, one juvenile fibro adenoma, and one lactating adenoma we had come a crossed. USG breast was initial aid of diagnosis followed by mammogram. FNAC was initial confirmatory diagnostic aid followed by excision biopsy.

Treatment: All the lesions were surgically excised. Local excision was done in all fibro adenoma. Wide local excision was done in small sized phyllodes tumour and simple mastectomy was done in large recurrent phyllodes and adenomyoepithelioma. Wide local excision to segmentectomy was done in case of fibrocystic disease of the breast.
\end{abstract}

Keywords: Benign breast disease - BBD, Medical Records Department - MRD, Simple mastectomy, Ultra sonogram (USG), Mammogram.

\section{Introduction}

Benign breast disease -BBD is a spectrum of diseases ranges from disorder to disease. Vast majority of breast lesions are benign. BBD constitute a heterogeneous group of lesions including developmental abnormalities, inflammatory lesions, epithelial and stromal proliferation, and neoplasms. Benign breast lesions present with a lump in the breast, pain, and nipple discharge. Most benign breast lesions occur in an age group of 35-45 years, incidentally it is also an age group of cancer. Presence of lump is a major concern to both patient and clinician because lump can likely to be malignant. Prime objective of a clinician is to rule out malignancy since breast cancer is most common malignant tumour in women however, benign breast lesions are more frequent than malignant lesions $(1,2)$. Most benign lesions are easily diagnosed by clinical examination. Ultrasound, mammography will help in the diagnosis of suspected benign lesions. FNAC, core needle biopsy and /or excision biopsy will confirm the diagnosis. All fibro adenoma lesions are treated by excision. Wide local excision is the choice in case of fibrocystic disease of the breast when suspected as malignant, wide local excision to mastectomy is preferred choice in case of phyllodes tumour.

\section{Aims and objectives}

1. To assess the prevalence of benign breast lesions in our area

2. To assess mode of presentation of BBD

3. To assess risks of developing subsequent cancer from benign lesions of the breast.

Type of Study: Retrospective/prospective study from January 2013 to December 2015.

Place of study: The study was undertaken in the Department of General Surgery, MediCiti Institute of Medical Sciences, Ghanpur, Medchal, Telangana State - India. 
Sample size: 145 female breast cases were analysed out of which 100 cases turned out as benign neoplasms of the breast.

Inclusion criteria: All women patients who were admitted in the general surgery department with breast lesions from 2013 January to 2015 December were included in this study.

Exclusion criteria: All the patients with congenital abnormalities, inflammatory conditions of the breast and breast carcinoma were excluded from the study.

\section{Material and Methods}

The data obtained from MRD, MediCiti Institute of Medical Sciences, a tertiary care hospital, Ghanpur, Medchal Mandal RR District. Telangan State, India. The data was compiled from patients who admitted with breast lesions, in the department of general surgery, from 2013 January to 2015 December. In the same period we admitted 1438 women patients for various diseases out of which 145 turned out as breast lesions, out of which 100 cases were diagnosed as benign breast neoplasms. Rest 45 cases were diagnosed as breast abscesses and carcinomas.

\begin{tabular}{|lccc|}
\hline Data obtained & & & \\
\hline Type of benign lesion & No. of cases & Percentage & Malignant changes \\
\hline Fibroadenoma & 70 & 70 & 00 \\
\hline Fibrocystic disease & 20 & 20 & 01 \\
\hline Phyllodes tumour & 08 & 08 & 03 \\
\hline Cystic lesion & 01 & 01 & \\
\hline Adenomyoepithelioma & 01 & 01 & \\
\hline
\end{tabular}

Fig.1. Observation - fibroadenoma is most common benign tumour

\begin{tabular}{|lcc|}
\hline Age incidence & & \\
\hline Age & No. of cases & Percentage \\
\hline$<20$ & 06 & 06 \\
\hline $21-30$ & 35 & 35 \\
\hline $31-40$ & 30 & 30 \\
\hline $41-50$ & 20 & 20 \\
\hline $51-60$ & 09 & 09 \\
\hline
\end{tabular}

Fig. 2. Observation - benign breast disease occur in $3^{\text {rd }} \& 4^{\text {th }}$ decade

\begin{tabular}{|lcc|}
\hline Breast involved & number & percentage \\
\hline Left breast & 60 & 60 \\
\hline Right breast & 40 & 40 \\
\hline Quadrant involved & Number & percentage \\
\hline UOQ & 64 & 64 \\
\hline LOQ & 26 & 26 \\
\hline UIQ & 10 & 10 \\
\hline
\end{tabular}

\begin{tabular}{|lll|}
\hline Mode of presentation & number & percentage \\
\hline Lump & 80 & 80 \\
\hline Pain & 10 & 10 \\
\hline Nipple discharge & 05 & 05 \\
\hline
\end{tabular}

Table 1: left breast and UOQ is more commonly involves than the right which is comparable with other studies.

As per our observation, most common benign lesions was fibroadenoma (70\%) followed by fibrocystic disease (20\%) and phyllodes tumour (08\%). We had come a crossed three fibro adenoma variants, one juvenile fibro adenoma, two giant fibro adenomas and one lactating adenoma. We had also come a crossed one adenomyoepithelioma which is a rare benign tumour of the breast. We included one plasma cell mastitis (though inflammatory swelling) in this study because it was presenting as diffuse hard mass where it was difficult differentiate from carcinoma of the breast. One cystic lesion also we come a crossed

\section{Observation}

Prevalence rate of benign breast neoplasms is $68 \%$ among all breast disease and prevalence rate of BBD is $6.9 \%$ among all diseases of women. BBD is more common in $3^{\text {rd }}$ and $4^{\text {th }}$ decade of life $(65 \%)$. Left breast $(60 \%)$ is more commonly involved than the right breast (40\%). Lump in the breast was most common presentation (80\%), definite palpable lump (100\%) was a feature in fibro adenoma, phyllodes tumour and adenomyoepithelioma however, fibrocystic disease presented as lumpy breast. Lump was located in the upper and outer quadrant of the breast (64\%) followed by lower outer (26\%) and upper inner quadrants (10\%). Pain in 
the breast is another symptom which was observed in 10 cases and nipple discharge in 5 cases. Pain and nipple discharge was exclusively present in fibrocystic disease.

\section{Discussion}

Benign breast disease (BBD) constitutes a heterogeneous group of lesions that include developmental abnormalities, inflammatory lesions, epithelial and stromal proliferative and benign neoplasms. BBD is most common problem among woman with a prevalence rate of $68 \%$ among all breast lesions. General prevalence rate among all diseases of women is $6.9 \%$. Benign breast lesions are more frequent than malignant lesions $(1,2)$.

BBD starts to rise in second decade of life, peaks in the third decade and declines thereafter, while incidence of carcinoma breast increases as age advances $(1,2)$. Fibro adenoma can present in young age group, less common in middle age group. Fibrocystic disease, phyllodes tumor and other rare tumors like adenomyoepithelioma commonly present in $3^{\text {rd }}$ and $4^{\text {th }}$ decade of life. In our study more number of BBD presented in $3^{\text {rd }}$ and $4^{\text {th }}$ decade of life followed by $5^{\text {th }}$ decade. Lump in the breast is most common presentation $(80 \%)$ followed by pain and nipple discharge.

Fibroadenoma is the most common benign neolam of the breast followed by fibrocystic disease of the breast and phyllodes tumour in order (3). Peak incidence occurs between the age group of 15 to 35 years. Fibroadenoma is thought to represent as a group of hyperplastic breast lobules called "aberrations of normal development and involution" (4). We observed different mode of presentation in young and, older individuals. The fibroadenoma occurring in young individuals is superficially placed in the breast, harder, multiple and sometimes bilateral. The fibroadenoma occurring in older people is soft, deeply placed, single and unilateral.

The neoplasm is hormone-dependent, that increases in size during lactation and pregnancy, and involutes along with rest of the breast in peri menopausal period (5). This phenomenon is particularly observed in lactating adenoma. The risk of development of fibroadenoma is claimed with usage of oral contraceptive pills before 20 years of age (5). We have come a crossed four fibro adenoma variants, one juvenile fibro adenoma, two giant fibro adenomas and one lactating adenoma. Complex fibro adenoma is a risk factor for development of breast cancer (6). Fibro adenomas in older women or in a women with a family history of breast cancer has higher incidence of developing breast cancer (7).

Fibrocystic disease, patient presents with lumpy breast rather classical lump. Pain (15\%) is the second most complaint followed by nipple discharge $(05 \%)$. Pain is predominant feature in some individuals and it is unbearable, needs immediate attention. Treating pai is not a easy job. Although the exact pathogenesis of the entity is not clear, hormonal imbalance, particularly oestrogen predominance over progesterone seems to play an important role in its development (8,9, and 10). Both ductal and lobular hyperplasia has relative risk factor for development of cancer breast, risk of developing malignancy from various studies ranging from 1.9 to $13.0 \%$ $(11,12)$. Radial scars on mammogram are nonspecific and may mimic as carcinoma. FNAC in such cases cannot rule out malignancy. Core biopsy is better over FNAC however excision biopsy is advised to have pool proof diagnosis (13-16). We excised one such lesion which was reported as BIRADS4 on mammogram, speculated with radial scaring, turned out as duct cell carcinoma of the breast.

Phyllodes tumour is third most common benign tumour of the breast in our study which is rapidly enlarging tumour, boselated surface with engorged veins. It is spectrum of disease ranging from fibro adenoma to benign phyllodes, metastasising benign and malignant phyllodes. Large rapidly growing and recurrent phyllodes tumours are likely to be malignant and may present with pain. Out of our eight Phyllodes tumours three turned out as malignant $(38 \%)$ and are all sarcomas.

Adenomyoepithelioma is very rare benign tumour of the breast. Clinically it is difficult to differentiate from carcinoma of the breast as it mimic as malignant lump with enlarged axillary lymph nodes in a middle aged woman. Recurrence rate is also high after wide excision. Most occasion patient need mastectomy.

FNAC will confirm the diagnosis in case of fibro adenoma, various studies show with average $86 \%$ specificity and 99\% sensitivity. Mammogram and less extent USG breast will aid in the diagnosis of fibrocystic disease and guided biopsy either FNA or core biopsy firm doubtful areas will confirm the diagnosis. Excision biopsy is mandate in case of mammographic findings are BIRADS $4 \& 5$ lesions, reported malignant rate in such case is as high as $50-90 \%(13,14)$.

Treatment: excision is the treatment of the choice in case of fibroadenoma however, USG guided cryoablation is advised, who does not want surgery (17). Fibrocystic disease is treated conservatively. Biopsy (either guided or wide excision) is advised from doubtful areas on mammography with presence of micro calcification, distorted breast architecture and radial

scarring. Phyllodes tumour pose considerable problem in treatment. Wide excision is treatment of choice in small lesions. The lesion $>5 \mathrm{~cm}$ need wide excision and large and recurring tumours require mastectomy (18, 19). We did mastectomy for our three cases of malignant phyllodes. 
Plasma cell mastitis though sub acute inflammatory lump but clinically the lump is totally confused as malignant lesion since it presents as hard lump with presence of pae de arrange and nipple retraction. Recurrence after excision is also a problem (20).

Over all breast lump is a concerned to a patient as well as clinician, prime responsibility of a clinician is to rule out malignancy. Most benign lumps occur in cancer age group except fibro adenoma which occur in young individuals. Clinically difficult differentiate benign to malignant lumps as they closely mimics as malignant lumps, particularly adenomyoepithelioma, plasma cell mastitis. It is difficult to differentiate from benign phyllodes to malignant phyllodes. Recurring rapidly growing phyllodes tumour is likely to be malignant.

\section{Conclusion}

Benign breast disease is more prevalent than malignancy of the breast and Prevalence rate is $68 \%$ among all breast disease and 6.9\% among all diseases of women. Most women need treatment in their life time. Lump in the breast is a concerned to both patient and clinician and to rule out malignancy is prime concerned. Compound fibroadenoma is a risk factor for development of breast cancer otherwise diagnosis is straight forward, excision in the treatment of choice. Fibrocystic disease is troublesome to a patient as for as pain is concerned however, malignancy has to be excluded since fibrocystic disease present as diffuse lump in a middle aged woman difficult to differentiate from carcinoma. Excision biopsy is ideal in such cases. Phyllodes tumour is known for its recurrence after wide excision and there is high chance of malignancy in recurring rapidly growing tumours where mastectomy is the option. Adenomyoepithelioma and plasma cell mastitis are though rare will be confused as malignant lump since both conditions closely mimic as carcinoma breast, needs special attention in diagnosis and treatment. Recurrence is more common after wide excision therefore mastectomy may be ideal option.

\section{References}

[1]. Donegan WL. (2002)Common benign conditions of the breast. In: Donegan WL, Spratt JS, eds. Cancer of the Breast, Fifth Edition. St. Louis, MO: Saunders: 67-110.

[2]. Kelsey JL, Gammon MD (1990) Epidemiology of breast cancer. Epidemiol Rev 12:228-240.

[3]. El-Wakeel H, Umpleby HC (2003) Systematic review of fibroadenoma as a risk factor for breast cancer. Breast 12:302-307.

[4]. Hughes LE, Mansel RE, Webster DJT. (1987) Aberrations of normal development and involution (ANDI): a new perspective on pathogenesis and nomenclature of benign breast disorders. Lancet 2:1316-1319.

[5]. Tavassoli FA, ed (1999) Chapter 11. Biphasic tumors. In: Pathology of the Breast, Second Edition. Stamford, CT: Appleton \& Lange 571-631.

[6]. El-Wakeel H, Umpleby HC. (2003) Systematic review of fibroadenoma as a risk factor for breast cancer. Breast 12:302-307.

[7]. Shabtai M, Saavedra-Malinger P, Shabtai EL et al. (2001) Fibroadenoma of the breast: analysis of associated pathological entities-a different risk marker in different age groups for concurrent breast cancer. Isr Med Assoc J 3:813-817

[8]. Santen RJ, Mansel R. (2005); Benign breast disorders. N Engl J Med; 353:275-285.

[9]. Love SM, Gelman RS, Silen W; (1982) Fibrocystic "disease" of the breast-a non-disease? N Engl J Med; 307:1010-1014.

[10]. Vorherr H. Fibrocystic breast disease: (1986) pathophysiology, pathomorphology, clinical picture, and management. Am J Obstet Gynecol; 154:161-179.

[11]. Hartmann LC, Sellers TA, Frost MH et al. (2005) Benign breast disease and the risk of breast cancer. N Engl J Med; 353:229-237.

[12]. Marshall LM, Hunter DJ, Connolly JL et al. (1997) Risk of breast cancer associated with atypical hyperplasia of lobular and ductal types. Cancer Epidemiol Biomarkers Prev; 6:297-301.

[13]. Kennedy M, Masterson AV, Kerin M et al. (2003) Pathology and clinical relevance of radial scars: a review. J Clin Pathol; 56:721724

[14]. Patterson JA, Scott M, Anderson N et al. (2004) Radial scar, complex sclerosing lesion and risk of breast cancer. Analysis of 175 cases in Northern Ireland. Eur J Surg Oncol; 30:1065-1068.

[15]. Fasih T, Jain M, Shrimankar J et al. (2005) All radial scars/complex sclerosing lesions seen on breast screening mammograms should be excised. Eur J Surg Oncol; 31:1125-1128.

[16]. Rabban JT, Sgroi DC.( 2004) Sclerosing lesions of the breast. Semin Diagn Pathol ; 21:42-47.

[17]. Caleffi M, Filho DD, Borghetti K et al. (2004) Cryoablation of benign breast tumours: evolution of technique and technology. Breast; 13:397-407.

[18]. Geisler DP, Boyle MJ, Malnar KF et al. (2000) Phyllodes tumors of the breast: a review of 32 cases. Am Surg; 66:360-366.

[19]. Chen WH, Cheng SP, Tzen CY et al. (2005) Surgical treatment of phyllodes tumors of the breast: retrospective review of 172 cases. J Surg Oncol; 91:185-194.

[20]. Heer R, Shrimankar j, Griffith CD (2003) Granulomatous mastitis can mimic breast cancer on clinical, radiological, or cytological examination: a cautionary tale. Breast; 12:283-286. 


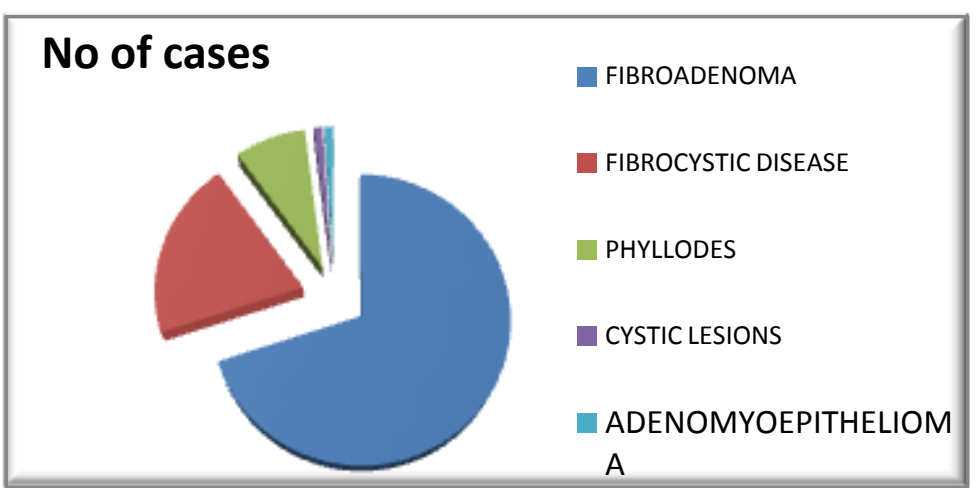

Fig.1. Observation - fibroadenoma is most common benign tumour

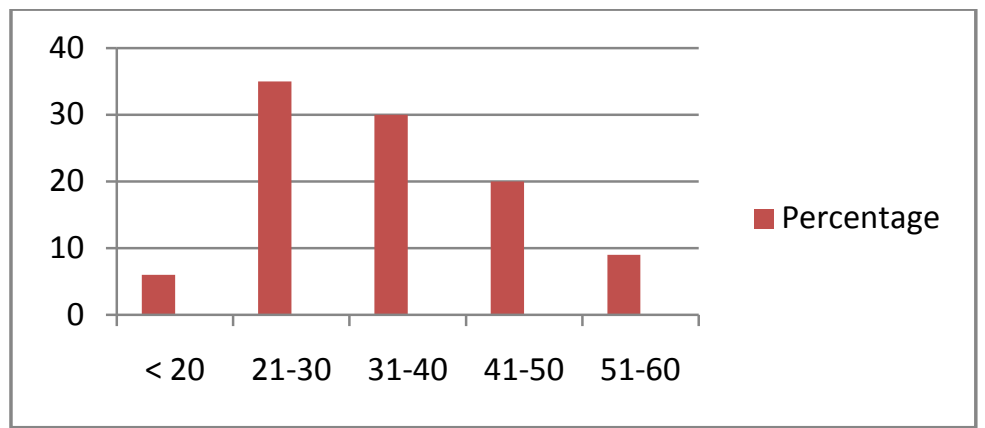

Fig. 2. Observation - benign breast disease occur in $3^{\text {rd }} \& 4^{\text {th }}$ decade

\begin{tabular}{|l|l|l|}
\hline Name of study & Breast involved & Quadrant involved \\
\hline Jaykar R D et al- (2013) & Left & UOQ \\
\hline Prajapati C L et al - (2014) & Left & UOQ \\
\hline Present study & Left & UOQ \\
\hline
\end{tabular}

Table 1: left breast and UOQ is more commonly involves than the right which is comparable with other studies.

\begin{tabular}{|l|l|}
\hline Study & Percentage of fibroadenomas \\
\hline Masood J M et al (2010) & $60.50 \%$ \\
\hline Ghafouri A et al (2006) & $68 \%$ \\
\hline Present study & $\mathbf{7 0 \%}$ \\
\hline
\end{tabular}

